\title{
CONTRIBUIÇÕES DA EDUCAÇÃO EMPREENDEDORA: O CASO DO EMPREENDE JOVEM FLUMINENSE
}

Elisângela Modesto Silva ${ }^{1}$

Robson Cunha ${ }^{2}$

Sandra Regina Holanda Mariano ${ }^{2}$

\footnotetext{
${ }^{1}$ Programa de Pós-Graduação Mestrado e Doutorado / Universidade Federal Fluminense

${ }^{2}$ Universidade Federal Fluminense
} 


\section{CONTRIBUIÇÕES DA EDUCAÇÃO EMPREENDEDORA: O CASO DO EMPREENDE JOVEM FLUMINENSE}

\section{Resumo}

Educar os jovens para uma sociedade em transformação vem ocupando a agenda de educadores e formuladores de políticas públicas educacionais em todo o mundo. No Brasil, a competência para empreender foi incorporada à $\mathrm{BNCC}$, servindo de referencia para o Programa Empreende Jovem Fluminense (EJF), desenvolvido para estudantes de ensino médio regular. Este artigo analisou as contribuições do EJF para o desenvolvimento de conhecimentos, habilidades e atitudes empreendedoras dos egressos da turma piloto, realizada em 2018. Foram coletados dados, por meio de entrevistas e grupos focais, identificando as percepções dos principais atores envolvidos. Concluiu-se que o desenvolvimento de habilidades não-cognitivas, como agir por iniciativa, criatividade, comunicação, autoconfiança, autoconhecimento e trabalho em equipe foram mais bem percebidas pela equipe escolar, organização parceira e pais. Melhorias em habilidades cognitivas para organização e planejamento foram observadas pelo principal docente do programa, que apontou certa imaturidade dos estudantes para colocar em práticas seus projetos empreendedores.

Palavras-Chave: empreendedorismo; educação empreendedora; ensino médio; jovens.

\section{Introdução}

A inclusão dos jovens no mercado de trabalho está no centro da agenda de governos, que vêm sendo cada vez mais desafiados a criarem oportunidades de trabalho produtivo e decente em suas sociedades (Lopes \& Teixeira, 2010). O tema é especialmente crítico quando se observa que a participação dos jovens nos postos de trabalho diminuiu drasticamente nos últimos vinte anos, de 55\% em 1997 para 45,7\% em 2017, segundo dados da Organização Internacional do Trabalho (OIT). Em 2017, a estimativa era de que 70,9 milhões de jovens estariam desempregados, ou seja, $13,1 \%$ da população jovem mundial. Uma estimativa futura alerta que entre 2017 e 2030, 25,6 milhões de jovens entre 15 e 29 anos entrarão no mercado de trabalho e precisarão de emprego (Organização Internacional do Trabalho, [OIT], 2017).

Este contexto tem sensibilizado os formuladores de políticas públicas para a inclusão da educação para o empreendedorismo nos currículos das escolas, com destaque para o ensino médio. Neste artigo, os termos educação para o empreendedorismo e educação empreendedora (EE) serão tratados como sinônimos. Sabe-se que historicamente a pesquisa sobre educação empreendedora tem privilegiado os estudos no âmbito da educação superior, cuja oferta de programas educacionais com este foco teve início nos anos 1960 nas escolas de negócio americanas (Béchard \& Grégoire, 2005, Fayolle, 2013, Pittaway \& Cope, 2007). Poucos estudos, entretanto, estão disponíveis quando se discute EE na educação básica. Neste campo, destacam-se pesquisadores de países escandinavos que têm discutido aspectos 
relacionados ao currículo, a metodologia, a formação docente, bem como avaliado os programas utilizando abordagens qualitativas e quantitativas (Ruskovaara, 2013, SeikkulaLeino, 2012).

No Brasil, a EE teve inicio na educação superior, e se desenvolveu por meio de um elevado número de iniciativas conduzidas por diferentes instituições de ensino superior (Endeavor, 2016). Um estudo realizado pela Endeavor mostrou grande diversidade de propostas pedagógicas focadas em educar o estudante sobre o que é o empreendedorismo, mas poucas se estendem para etapas em que o estudante vivencia o processo empreendedor (Endeavor, 2016). Na educação básica, o ensino de empreendedorismo tem ocorrido em iniciativas dispersas em todo país, conduzidas por escolas e redes de escolas, principalmente por meio de parceria com organizações como SEBRAE e Junior Achievement. No ensino fundamental, destaca-se a iniciativa "pedagogia empreendedora", desenvolvida por Fernando Dolabela, disseminada em escolas em várias partes do Brasil (Dolabela \& Fillion, 2013). Desta forma, pode-se dizer que, de forma geral, o ensino de empreendedorismo na educação básica é variado e distinto entre si, seja nas estratégias como a inclusão de componentes curriculares específicos, seja na forma como o conteúdo é tratado, de forma transversal ou pontual (Silva, 2015).

Todavia, o ensino de empreendedorismo na educação básica foi alçado a novo patamar com a introdução da Base Nacional Comum Curricular (BNCC), em 2017. A preocupação do regulador brasileiro em incluir conteúdos do campo do empreendedorismo responde aos desafios apontados por diversas pesquisas, como a desenvolvida pelo Banco Mundial (Almeida \& Packard, 2018), em que se afirma que mais de $60 \%$ dos jovens brasileiros, com 15 anos, iniciam o ensino médio com lacunas significativas de aprendizagem e altas taxas de distorção idade-série. Estes resultados fortalecem a ideia de que a escola não tem sido capaz de atrair o estudante, que abandona os estudos por falta de interesse no que a escola oferece (Neri, 2009).

É neste contexto que o Programa Empreende Jovem Fluminense (EJF) foi desenvolvido pela Universidade Federal Fluminense (UFF), com a poio da Secretaria de Estado da Educação do Rio de Janeiro (SEEDUC) e da Organização Social REAME. Seu objetivo é proporcionar aos estudantes conhecimentos, habilidades e atitudes para agir de forma empreendedora, o que representa uma competência essencial para a vida e não apenas para a criação de um negócio (Moberg et al., 2014). O programa contemplou 60 jovens estudantes do ensino médio de escolas estaduais da cidade de São Gonçalo, indicadas pela Secretaria de Estado de Educação do Rio de Janeiro, que frequentaram a turma piloto durante o ano de 2018.

Os estudantes que manifestaram interesse em participar do curso escreveram uma redação na qual discorriam sobre sua motivação para participar do EJF, e então, foram selecionados por sorteio. O Programa EJF foi organizado em cinco disciplinas, a saber: Competências Empreendedoras (60h), Mercado Digital (45h), Modelagem de Negócios (30h), Viabilidade de Projetos (45h) e Projeto Integrador (60h). Tais disciplinas foram oferecidas em dois semestres, uma de cada vez, na ordem apresentada acima, totalizando carga horária de 240 horas. Foram desenvolvidos materiais instrucionais específicos, disponibilizados no ambiente virtual de aprendizagem. Adotou-se a modalidade semipresencial, com encontros presenciais quinzenais, com duração de três horas, realizados no Campus do Valonguinho, no 
centro de Niterói (RJ). A organização da logística para a participação dos estudantes em tais encontros ficou a cargo da instituição parceira REAME, que contou com o apoio de recursos do Programa Criança Esperança.

Este artigo tem o objetivo de apresentar os resultados obtidos após a execução da turma piloto do programa EJF, especialmente no que se refere a contribuição desta iniciativa de educação para o empreendedorismo para o desenvolvimento da mentalidade empreendedora dos alunos que frequentaram o programa durante o ano de 2018. Os dados foram coletados, através de entrevistas e grupos focais com os atores envolvidos na execução do programa: (i) gestores escolares, (ii) alunos, (iii) pais de alunos, (iv) professores do programa EJF e (v) profissionais do parceiro REAME.

\section{Fundamentação Teórica}

\subsection{Educação Empreendedora no Brasil e no Mundo}

A Europa alçou o empreendedorismo ao topo da sua agenda de desenvolvimento em 2003, como o lançamento do "Livro Verde sobre Empreendedorismo na Europa". Desde então vem desenvolvendo sua estratégia de educação para o empreendedorismo que culminou, em 2018, com a publicação do Quadro de Referência para Competências Empreendedoras EntreComp, (McCallum, Weicht, McMullan \& Price, 2018). Os europeus definiram que:

"a educação para o empreendedorismo refere-se ao desenvolvimento das competências dos aprendizes e à sua capacidade para transformar ideias criativas em ações empreendedoras. Trata-se de uma competência essencial para todos os aprendizes, que contribui para o desenvolvimento pessoal, cidadania ativa, inclusão social e empregabilidade. É relevante para o processo de aprendizagem ao longo da vida, em todas as disciplinas e para todos os tipos de educação e de formação (formal, não formal e informal) que contribuem para um espírito ou comportamento empreendedores, com ou sem finalidades comerciais" (Comissão Europeia/EACEA/Eurydice, 2016, p. 21).

Johansen e Schanke (2014) informam que na última década houve aumento substancial da oferta de EE na educação básica. Oito países europeus lançaram estratégias específicas sobre EE, enquanto outros escolheram estratégias educacionais ou econômicas mais amplas que incorporam objetivos para EE. Segundo os autores, na Noruega o empreendedorismo é um tema abordado em várias disciplinas e integrado através de projetos interdisciplinares de empreendedorismo, que se organizam por meio do "Programa de Empresa" (CP - sigla em inglês para Company Programme) desenvolvido pela Junior Achievement - Young Enterprise (JA-YE) norueguesa, que resultam na criação de "mini empresas" pelos estudantes.

Na Austrália, escolas do estado de Vitória se organizaram, em 2015, sob a liderança do professor Yong Zhao, para implementar e avaliar programas de EE, motivados pela necessidade de mudar o paradigma educacional de forma a cultivar uma mentalidade orientada para ação empreendedora por parte dos estudantes (Andersen, Hinz \& Matus, 2017). 
No cenário brasileiro, os desafios da educação dos jovens são significativos. Resultados da edição de 2015 do Programa Internacional de Avaliação de Estudantes (PISA, da sigla em inglês) apontam que o Brasil obteve pontuações bem abaixo da média dos quase 70 países avaliados nas áreas de ciências, leitura e matemática (Ministério da Educação [MEC], 2016). A média geral dos demais países em ciências foi de 493 pontos, o Brasil apresentou um resultado de 401 pontos, ficando em $63^{\circ}$ lugar no ranking, já em leitura, a média geral também foi de 493 pontos, o Brasil ficou em 59 lugar no ranking com 407 pontos e em matemática a média geral foi de 490 pontos e o Brasil, que apresentou a primeira queda de pontuação desde 2003, ficou em $66^{\circ}$ lugar no ranking com 377 pontos (MEC, 2016).

Para mudar o cenário da educação brasileira, o Ministério da Educação propôs, entre outras ações, reformar o ensino médio e implantar uma Base Nacional Comum Curricular (MEC, 2016), por meio da medida provisória 746 de 2016, transformada em lei, que revogou parte das diretrizes e bases da educação nacional (Lei $n^{\circ}$ 9.394, de 20 de dezembro de 1996) e introduziu mudanças na estrutura do ensino médio. Dentre as principais mudanças destacamse o formato, a carga horária e a flexibilização de conteúdos e disciplinas. A BNCC definiu que $60 \%$ dos conteúdos são obrigatórios para todos os estudantes, com 1.800 horas, e 40\%, 1.200 horas, integrarão percursos formativos variados. (MEC, 2019).

Os conteúdos obrigatórios foram estruturados em quatro áreas centrais: Linguagens e suas Tecnologias, Matemática e suas Tecnologias, Ciências da Natureza e suas Tecnologias, Ciências Humanas e Sociais Aplicadas (MEC, 2019). Os itinerários formativos, que devem favorecer o protagonismo juvenil, foram estruturados em quatro eixos, a saber: (i) investigação científica, (ii) processos criativos, mediação e (iii) intervenção sociocultural e (iv) empreendedorismo. (BNCC, 2017).

A introdução de conteúdos de empreendedorismo na Base coloca o Brasil em sintonia com as tendências observadas nos sistemas de ensino dos países da Organização para a Cooperação e Desenvolvimento Econômico (OCDE), cujo foco da educação para o empreendedorismo está nas práticas de ensino que visam criar e aprimorar as habilidades dos alunos para agir com responsabilidade, serem ativos, criativos, capazes de aproveitar oportunidades, avaliar e assumir riscos controlados, planejar e gerenciar projetos de tamanhos adequados (Hoare \& Ruskovaara, 2015). Desta forma, os currículos devem refletir a atitude de "posso fazer" que a EE pretende encorajar.

\subsection{Educação Empreendedora no Ensino Médio}

Vivendo em um mundo interconectado, diverso e em rápida transformação, o estudante do século XXI tem sua vida moldada diariamente por forças emergentes de diversas naturezas econômicas, digitais, culturais, demográficas e ambientais (OCDE, 2018). Além de aprender a participar de um mundo mais interconectado, o jovem deve também examinar questões locais, globais e interculturais, entender e apreciar diferentes perspectivas e visões de mundo, interagir com sucesso e respeitosamente com os outros e tomar uma ação responsável em direção à sustentabilidade e ao bem-estar coletivo (Programme for International Student Assessment [PISA], 2018, pg. 4). De acordo com a OCDE, as escolas desempenham um papel crucial em ajudar os jovens a desenvolver competência global.

Para Lackéus, 2015, competências empreendedoras devem ser desenvolvidas especialmente nos níveis ensino fundamental e médio. Johansen e Schanke (2014) sugerem 
que nos primeiros anos de educação básica a EE deve focalizar o desenvolvimento da criatividade, iniciativa e autoconfiança, adotando uma abordagem baseada em projetos. Já a partir do nível do ensino médio, a EE pode ser ensinada como um assunto à parte e se concentrar mais em desenvolver as habilidades e o know-how para estruturar e administrar uma empresa.

Vários pesquisadores apontam que a principal contribuição da EE é preparar os jovens para entrar no mercado de trabalho, bem como desenvolver um senso de iniciativa e habilidades empreendedoras (Lackéus, 2015, Moberg et. al., 2014). Entretanto, o agir empreendedor não se restringe a criação de empresas, mas a geração de valor para a sociedade (Lackéus, 2015). Em toda Europa, observa-se a implementação de medidas para aumentar a disseminação e a qualidade da EE (Johansen \& Schanke, 2014).

No Brasil, a BNCC se organiza em direitos de aprendizagem, expressos em dez competências, que guiam o desenvolvimento escolar das crianças e dos jovens desde a creche até o Ensino Médio. A Tabela 1 apresenta as competências determinadas pela BNCC.

\section{Tabela 1}

\section{Competências gerais da Educação Básica, estabelecidas pela BNCC}

\section{Competência}

Conhecimento Objetivo

Valorizar e utilizar os conhecimentos historicamente construídos sobre o mundo físico, social, cultural e digital para entender e explicar a realidade, continuar aprendendo e colaborar para a construção de uma sociedade justa, democrática e inclusiva.

Pensamento científico, crítico Exercitar a curiosidade intelectual e recorrer à abordagem própria das ciências, e criativo incluindo a investigação, a reflexão, a análise crítica, a imaginação e a criatividade, para investigar causas, elaborar e testar hipóteses, formular e resolver problemas e criar soluções (inclusive tecnológicas) com base nos conhecimentos das diferentes áreas.

Repertório cultural Valorizar e fruir as diversas manifestações artísticas e culturais, das locais às mundiais, e também participar de práticas diversificadas da produção artísticocultural.

Comunicação Utilizar diferentes linguagens - verbal (oral ou visual-motora, como Libras, e escrita), corporal, visual, sonora e digital -, bem como conhecimentos das linguagens artísticas, matemática e científica, para se expressar e partilhar informações, experiências, ideias e sentimentos em diferentes contextos e produzir sentidos que levem ao entendimento mútuo.

Cultura digital Compreender, utilizar e criar tecnologias digitais de informação e comunicação de forma crítica, significativa, reflexiva e ética nas diversas práticas sociais (incluindo as escolares) para se comunicar, acessar e disseminar informações, produzir conhecimentos, resolver problemas e exercer protagonismo e autoria na vida pessoal e coletiva.

Trabalho e Projeto de Vida Valorizar a diversidade de saberes e vivências culturais e apropriar-se de conhecimentos e experiências que lhe possibilitem entender as relações próprias do mundo do trabalho e fazer escolhas alinhadas ao exercício da cidadania e ao seu projeto de vida, com liberdade, autonomia, consciência crítica e responsabilidade.

Argumentação Argumentar com base em fatos, dados e informações confiáveis, para formular, negociar e defender ideias, pontos de vista e decisões comuns que respeitem e promovam os direitos humanos, a consciência socioambiental e o consumo responsável em âmbito local, regional e global, com posicionamento ético em 


\begin{tabular}{ll}
\hline & relação ao cuidado de si mesmo, dos outros e do planeta. \\
\hline Autoconhecimento e & Conhecer-se, apreciar-se e cuidar de sua saúde física e emocional, \\
Autocuidado & compreendendo- se na diversidade humana e reconhecendo suas emoções e as dos \\
& outros, com autocrítica e capacidade para lidar com elas. \\
\hline Empatia e Cooperação & $\begin{array}{l}\text { Exercitar a empatia, o diálogo, a resolução de conflitos e a cooperação, fazendo- } \\
\text { se respeitar e promovendo o respeito ao outro e aos direitos humanos, com }\end{array}$ \\
& $\begin{array}{l}\text { acolhimento e valorização da diversidade de indivíduos e de grupos sociais, seus } \\
\text { saberes, identidades, culturas e potencialidades, sem preconceitos de qualquer } \\
\text { natureza. }\end{array}$ \\
\hline Responsabilidade e Cidadania & $\begin{array}{l}\text { Agir pessoal e coletivamente com autonomia, responsabilidade, flexibilidade, } \\
\text { resiliência e determinação, tomando decisões com base em princípios éticos, } \\
\text { democráticos, inclusivos, sustentáveis e solidários. }\end{array}$ \\
\hline
\end{tabular}

Fonte: Ministério da Educação, BNCC, 2017. (adaptado pelos autores)

O principal papel dos programas de EE é aumentar a conscientização dos estudantes, destacar o caminho empreendedor como uma opção de carreira viável e desenvolver atitudes positivas, conhecimentos e habilidades empreendedoras (Moberg, et al., 2014). Para Hoare e Ruskovaara (2015) o foco deve estar nas práticas de ensino que visam criar e aprimorar as habilidades dos alunos para agir com responsabilidade, serem ativos, criativos, capazes de aproveitar oportunidades, avaliar e assumir riscos controlados, planejar e gerenciar projetos de tamanhos adequados.

O sistema educacional tem uma longa tradição de enfoque em habilidades e conhecimentos de ensino, mas quando se trata de ensinar empreendedorismo, também é importante abordar elementos como a mentalidade dos estudantes, atitudes e aspirações de carreira (Moberg et al., 2014). Estas abordagens se originam, em grande medida, do campo da pesquisa em empreendedorismo e seus métodos de ensino são inspirados pelas habilidades empreendedoras e a maneira como empreendedores aprendem (Moberg, 2014).

Entretanto, é válido pontuar que uma proposta de EE é comumente classificada em três abordagens: (i) educação sobre empreendedorismo, que trata de conteúdos que abordam o que é empreendedorismo e o que os empresários fazem; (ii) educação para o empreendedorismo, que busca orientar para o trabalho ao objetivar desenvolver habilidades cognitivas e conhecimentos necessários para uma personalidade empreendedora e; (iii) educação através do empreendedorismo, que usa o empreendedorismo como método de ensino ao promover experiências que fazem o estudante vivenciar o processo empreendedor, o que promove habilidades não-cognitivas, afeta o envolvimento escolar dos alunos e a intenção de seguir uma carreira como autônomo. (Moberg, 2014).

\section{Procedimentos Metodológicos}

O presente estudo se caracteriza por ser exploratório e descritivo. Segundo Gil (2002), pesquisas exploratórias proporcionam maior familiaridade com o problema, com vistas a torná-lo mais explícito ou a constituir hipóteses. Também têm como objetivo principal o aprimoramento de ideias ou a descoberta de intuições. Pesquisas descritivas são, juntamente com as exploratórias, as que habitualmente realizam os pesquisadores sociais preocupados com a atuação prática (Gil, 2002), além disso, pesquisas descritivas identificam os fatores que contribuem ou determinam a ocorrência dos fenômenos (Gerhardt \& Silveira, 2009). 
Este trabalho de abordagem qualitativa foi realizado por meio de um estudo de caso, com o objetivo de avaliar a contribuição de um programa de educação empreendedora para jovens, matriculados no ensino médio, em escolas estaduais do município de São Gonçalo, no estado do Rio de Janeiro, na perspectiva dos atores envolvidos.

Optou-se por realizar um estudo de caso, pois, desse modo, é possível alcançar um conhecimento mais amplo sobre o objeto de estudo, dissipar dúvidas, esclarecer questões pertinentes e instruir ações posteriores (Chizzotti, 2006). O estudo de caso tem sido utilizado em todos os domínios das atividades econômicas e sociais (Yin, 2003) e adota diversos recursos para coleta das informações sobre a temática de estudo. No estudo de caso o pesquisador não intervém sobre o objeto a ser estudado, mas, revela-o tal como ele o percebe e apresenta uma perspectiva global tanto quanto completa e coerente do objeto estudado (Fonseca, 2002).

Os recursos escolhidos para a coleta das informações foram entrevistas semiestruturadas, que foram realizadas de forma individual, com os indivíduos descritos na Tabela 2 e em grupos, por meio de grupos focais. Todos os dados foram coletados em 2018. As perguntas foram organizadas em um roteiro sobre o tema a ser estudado, e, durante as entrevistas os participantes foram incentivados a falar livremente de acordo com o desdobramento do tema principal (Gerhardt \& Silveira, 2009).

\section{Tabela 2}

\section{Descrição dos entrevistados}

\begin{tabular}{|c|c|c|c|c|}
\hline Ator & Sexo & Idade & Formação & Cargo \\
\hline \multirow[t]{2}{*}{ Gestão da Escola 1} & Feminino & 66 & $\begin{array}{l}\text { Pedagogia, especialista em } \\
\text { educação. }\end{array}$ & Orientadora Educacional \\
\hline & Feminino & 43 & Letras. & $\begin{array}{l}\text { Coordenadora } \\
\text { Pedagógica }\end{array}$ \\
\hline \multirow[t]{2}{*}{ Gestão da Escola 2} & Feminino & 60 & $\begin{array}{l}\text { Pedagogia, pós-graduada } \\
\text { em desenvolvimento e } \\
\text { aprendizagem }\end{array}$ & Diretora \\
\hline & Feminino & 55 & Educação Física & Articuladora Pedagógica \\
\hline \multirow[t]{2}{*}{ Gestão da Escola 3} & Masculino & 46 & $\begin{array}{l}\text { Letras e MBA em gestão } \\
\text { empreendedora }\end{array}$ & Diretor \\
\hline & Feminino & 52 & $\begin{array}{l}\text { Pedagogia e } \text { MBA em } \\
\text { gestão empreendedora }\end{array}$ & Orientadora Educacional \\
\hline \multirow[t]{4}{*}{ Organização REAME } & Feminino & 50 & Assistente Social & Diretora \\
\hline & Feminino & 38 & Assistente Social & Coordenadora Técnica \\
\hline & Masculino & 37 & Psicologia & Psicólogo \\
\hline & Masculino & 32 & Administração & Auxiliar Administrativo \\
\hline Docente EJF & Masculino & 30 & Administração & Docente \\
\hline
\end{tabular}

A pesquisa, ora apresentada, foi realizada em quatro etapas: 1) Estudo bibliográfico acerca dos temas empreendedorismo e educação empreendedora para construção do referencial teórico básico da pesquisa; 2) Coleta de dados juntos aos estudantes e demais atores envolvidos no Programa EJF; 3) Transcrição das respostas obtidas nas entrevistas individuais e em grupo; 4) análise dos dados. 


\subsection{Tratamento de dados e definição de categorias}

Os áudios produzidos a partir das entrevistas individuais e em grupo foram transcritos, para posterior leitura, categorização e análise dos conteúdos. A ferramenta utilizada para a categorização e análise dos dados coletados foi a análise de conteúdo, que consiste em um conjunto de técnicas de análise das comunicações que utiliza procedimentos sistemáticos e objetivos de descrição do conteúdo das mensagens (Bardin, 1977). O objetivo da análise de conteúdo, segundo Bardin (1977) é a manipulação de mensagens (conteúdo e expressão desse conteúdo) para evidenciar os indicadores que permitam inferir sobre outra realidade que não a da mensagem.

Bardin (1977) recomenda que a análise seja feita em três etapas: a) pré-análise: que envolve a organização e escolha dos documentos a serem analisados e o momento em que se realiza a leitura flutuante; b) exploração do material: onde se realiza a codificação e enumeração dos dados através da análise temática, que permite atingir uma representação do conteúdo e categorizar os dados por analogia ou por diferenciação; c) tratamento dos resultados, inferências e interpretação: momento em que o analista pode propor inferências e adiantar interpretações a propósito dos objetivos, do embasamento teórico ou de descobertas inesperadas.

A análise dos conteúdos foi feita de forma transversal (Bardin, 1977), ou seja, foi recortado do texto tudo que foi afirmado referente ao objeto em estudo - a contribuição da educação empreendedora para jovens - e organizado em tabelas de acordo com as categorias definidas.

Na etapa da pré-análise, proposta por Bardin, 1977, uma das missões é a escolha do corpus, que é o conjunto de documentos que serão submetidos aos procedimentos analíticos. A escolha dos documentos deve obedecer a 3 regras, a saber (i) Regra da exaustividade - uma vez definido o corpus, deve-se ter em conta todos os documentos referente ao tema. (ii) Regra da representatividade - a análise pode ser efetuada por amostragem. (iii) Regra da homogeneidade - todos os documentos tratam do mesmo tema, foram obtidas pela mesma técnica que foi realizada pela mesma pessoa. (iv) Regra da pertinência - os documentos devem ser adequados enquanto fonte de informação.

O corpus referente a este estudo - transcrições das entrevistas - está enquadrado na regra de homogeneidade, pois são semelhantes entre si, e, esta regra permite que sejam alcançados resultados globais ou que se comparem os resultados individuais.

A segunda etapa da análise de conteúdo proposta por Bardin trata da exploração do material, nesta etapa o material é analisado em profundidade e é possível realizar a categorização dos temas. Segundo Bardin, 1977, categorização é uma operação de classificação de elementos constitutivos de um conjunto por diferenciação e seguidamente, por reagrupamento segundo o gênero, com critérios previamente definidos. Quanto aos critérios, a categorização pode ser (i) semântica (temáticas), (ii) sintático (verbos e adjetivos), (iii) léxico (sentido das palavras) e (iv) expressivo (classifica as diversas perturbações da linguagem).

Neste estudo a categorização seguiu o critério semântico, pois foram definidas as categorias temáticas principais e os achados relacionados àquela categoria, validados através do destaque dos trechos das entrevistas realizadas durante a coleta de dados. As categorias temáticas principais encontradas foram: (i) Motivação dos alunos para se inscreverem no 
Programa Empreende Jovem Fluminense (EJF); (ii) Conhecimentos, habilidades e atitudes empreendedoras desenvolvidas; e (iii) Mudança de comportamento dos estudantes.

\section{Resultados}

Os resultados apresentam as percepções de cada um dos atores que participaram da iniciativa analisadas à luz das categorias de análise apresentadas anteriormente.

\subsection{Percepções dos diretores e coordenadores das escolas participantes}

Todos os entrevistados concordaram que houve melhora significativa no comportamento dos alunos que estavam frequentando o Programa EJF, especialmente no que se refere a atitudes como autoconsciência demonstrada pelo agir de forma mais organizada, e mostrarem mais foco em sala de aula. Notaram que alunos que eram mais impulsivos estavam mais calmos, o que sugeriu o desenvolvimento de autocontrole sobre a impulsividade e o bom comportamento em relação ao próximo, parecendo demonstrar maior confiança social. Também foram unânimes os relatos de que o gênero feminino foi mais impactado pela educação empreendedora. Os entrevistados acreditam que a explicação para isso é que as jovens são mais agitadas, interessadas e têm mais ânsia pelo saber.

Os relatos também sugeriram que houve uma abertura para consciência empreendedora através da percepção de como empreendedores pensam e agem, desta forma, percebeu-se também o despertar para o comportamento autônomo, de agir por iniciativa, liderança e protagonismo nas ações.

Dentro desse contexto, observamos também que competências do itinerário empreendedorismo da BNCC podem ser relacionadas aqui, como, comunicação, argumentação, empatia e cooperação (BNCC, 2017).

Em sentido amplo, Programas de Educação Empreendedora (PEE) são definidos como qualquer processo pedagógico de desenvolvimento de habilidades e atitudes empreendedoras, e envolve desenvolvimento de certas qualidades pessoais, não somente a criação de novos negócios (Fayolle, Gailly \& Lassas-Clerc, 2006). Para Chen, et al., 2013, a EE reúne sistemas educacionais e cultiva a consciência empreendedora, o pensamento e as habilidades por meio de métodos educacionais.

Neste sentido, sobre a contribuição da EE, os entrevistados concordaram que é um processo de mudança de comportamento, que nasce de dentro para fora e um investimento no desenvolvimento pessoal, não necessariamente tem como resultado imediato a criação de uma empresa.

No passado a EE se limitava a ensinar estudantes sobre como criar novos empreendimentos. Contemporaneamente, os PEE vêm cada vez mais se propondo a capacitar pessoas para lidar com a incerteza e ambiguidade do contexto contemporâneo em que vivemos, de forma que sejam capazes de iniciar, construir e levar a cabo iniciativas, em um processo de não apenas lidar com as mudanças, mas se antecipar a elas ou mesmo as iniciar. Isto quer dizer que o empreendedorismo não trata apenas de ensinar a "criar uma empresa e fazer negócio", mas também de formar pessoas empreendedoras de forma mais ampla. De acordo com McCullum et al. (2018) a educação para o empreendedorismo está voltada tanto para o contexto profissional e empresarial, como para o contexto geral da vida de um 
indivíduo. Portanto, a empregabilidade também deve ser um objetivo de todos os tipos de estratégia para EE.

Sobre os estudantes que frequentaram o EJF, de acordo com as percepções dos gestores das escolas, sintetiza-se que as contribuições do EJF ficaram no âmbito das competências agir por iniciativa, comunicação, organização, autoconfiança, autoconhecimento e trabalho em equipe. Os jovens apresentaram certo protagonismo para a resolução de problemas e proposta de soluções para situações do cotidiano dentro e fora da escola. Desta forma, os achados mostram que os diretores e coordenadores pedagógicos das escolas que participaram da iniciativa perceberam mudanças no comportamento dos jovens que participaram do EJF relacionadas ao desenvolvimento de competências não cognitivas.

Ao serem questionados sobre se houve melhora no rendimento escolar, não houve consenso. Alguns afirmaram que a média de notas dos estudantes não se alterou e outros apontaram que o sentido de organização adquirido depois do curso influenciou positivamente a forma dos estudantes lidarem com as demais disciplinas, o que pode ser um fator determinante para a melhora dos resultados na escola.

\subsection{Percepções dos alunos que frequentaram o programa EJF}

Os entrevistados destacaram os cuidados que as equipes de professores do EJF tiveram com eles durante as aulas. Valorizaram o profissionalismo com que os conteúdos foram ministrados e o nível de conhecimento da equipe de docentes. Estes fatores os mantiveram interessados e motivados em frequentar as aulas.

Para Moberg et. al, 2014 o relacionamento com colegas e professores e importante para que os alunos percebam a educação como algo que tem propósito e é útil. Esta percepção positiva impacta variáveis como saúde, taxas de desistência, desempenho acadêmico e status socioeconômico dos estudantes.

Importante ressaltar que a abordagem de ensino do curso Empreende Jovem Fluminense - Educação para o Empreendedorismo - buscou orientar para o trabalho ao objetivar desenvolver habilidades cognitivas e conhecimentos necessários para uma personalidade empreendedora (Moberg, 2014).

Desta forma, ao serem questionados sobre conhecimentos, habilidades e atitudes percebidas e desenvolvidas durante o curso, os jovens relataram que se sentiam mais criativos, organizados, com mais inciativa, apontaram também melhora na habilidade de se comunicar e maior disposição para trabalhos em equipe. Assim como os relatos dos diretores e coordenadores das escolas, apresentados na sessão 4.1, os estudantes também perceberam que houve maior engajamento nas atividades escolares, aproximação com os professores, comentários durante as aulas, busca por coisas novas e proposta de soluções para situações cotidianas.

O itinerário formativo empreendedorismo, chancelado pela BNCC, 2017 enfatiza a expansão da capacidade do estudante em mobilizar conhecimentos de diferentes áreas, a fim de empreender projetos pessoais ou produtivos articulados ao seu projeto de vida, buscando desenvolver autonomia, foco e determinação para que consigam planejar e conquistar objetivos pessoais ou criar empreendimentos (BNCC, 2017).

Nessa perspectiva podemos verificar já um discreto desenvolvimento de uma mentalidade empreendedora, que é estar focado em ação e responsabilidade, trata da 
importância do aluno compreender o seu papel como agente ativo e criador do seu futuro (Moberg et al., 2014). Também podemos identificar o desenvolvimento da mentalidade empreendedora na categoria visão de sentido na ação, onde os relatos ilustram preocupação com o futuro e com a carreira a seguir.

Conectividade com a carreira futura também foi uma área avaliada e percebida pelos respondentes. Os relatos apresentados na categoria visão de sentido na ação mostram que os estudantes perceberam propósito nos trabalhos escolares e como, através desses conhecimentos, podem usar o conhecimento e as habilidades de forma prática em sua vida cotidiana presente e futura (Moberg et al., 2014).

Sobre contribuição da EE para melhora no desempenho acadêmico, Johansen e Schanke (2014) relatam que projetos de empreendedorismo mais focados no desenvolvimento de habilidades interpessoais podem ser mais adequados para melhora do desempenho escolar, por outro lado, projetos com foco em desenvolvimento de habilidades e know-how para montar e desenvolver negócios contribui pouco para a melhoria do desempenho acadêmico.

Para os jovens do curso EJF não houve consenso sobre a contribuição do EJF para a melhoria do desempenho acadêmico de forma geral. Os que se manifestaram, atribuíram a melhora à forma como têm se organizado para estudar, depois dos conhecimentos sobre organização que o curso proporcionou. Os coordenadores das escolas tiveram a mesma percepção, conforme relatado na sessão 5.1.

\subsection{Percepções dos parceiros da iniciativa EJF}

A percepção dos entrevistados foi de que os alunos se tornaram mais proativos em suas ações, demonstraram maior envolvimento nas atividades escolares, se organizado melhor para os estudos e empreendendo ações em conjunto, o que sugere o desenvolvimento da criatividade e do trabalho em equipe. Durante a entrevista houve o relato de uma gincana realizada entre as escolas, promovida pela organização REAME, para arrecadação de garrafas PET.

Os estudantes das três escolas que estavam participando do programa tomaram a iniciativa de coordenar e divulgar a campanha dentro da escola e empreenderam ações de organização e turnos para arrecadação das garrafas, divulgação nas turmas e um dos grupos inovou ao perceber que ao amassarem as garrafas conseguiriam armazenar maior número nas ecobegs fornecidas para a realização da gincana.

Após estes relatos podemos reafirmar que competências empreendedoras relacionadas a criatividade, iniciativa e organização foram desenvolvidas.

\subsection{Percepções do principal docente do curso EJF e pais de alunos}

As percepções do principal docente que atuou na turma piloto giraram em torno da reflexão sobre a forma correta de aplicação do conteúdo para a efetiva apreensão do conteúdo e sobre a evolução dos estudantes na transição do primeiro semestre do curso para o segundo.

A segunda etapa do curso EJF propunha uma abordagem mais prática, onde os alunos deveriam efetivamente criar uma proposta de negócio. O modelo escolhido para o planejamento do negócio foi o CANVAS, que é uma ferramenta de gerenciamento estratégico, que permite desenvolver e esboçar modelos de negócio novos ou existentes. Ao ser questionado sobre como estava percebendo o desenvolvimento e o aprendizado dos estudantes nessa segunda etapa do curso, o entrevistado disse que já no primeiro encontro 
verificou que a dinâmica das aulas deveria ser alterada, pois os alunos ainda não estavam amadurecidos em suas propostas de negócios.

Destacou que já no segundo encontro, com a aula mais prática, os estudantes tiveram um aproveitamento melhor, e ficaram mais motivados.

O entrevistado também mudou a forma de utilização da plataforma online, solicitando aos alunos que as tarefas a serem realizadas fora de sala de aula, para entrega no próximo encontro, fossem enviadas com antecedência para os monitores. Com essa estratégia os alunos ampliaram a habilidade de organização, planejamento e adquiriram maior responsabilidade.

Após as ações de mudança da dinâmica dos encontros o docente percebeu mais iniciativa e proatividade nos grupos, além de maior clareza sobre os objetivos das propostas de negócios.

Para o entrevistado, a maior contribuição do curso EJF foi o acesso a ferramentas que possibilitaram desenvolver habilidades de gestão, organização e planejamento. Para o docente, tais ferramentas auxiliam não só na ideia de um empreendimento, mas, principalmente na condução de questões do dia a dia. A opinião do entrevistado culmina com os objetivos do itinerário empreendedorismo da BNCC de expandir a capacidade do estudante em mobilizar conhecimentos de diferentes áreas, a fim de empreender projetos pessoais ou produtivos articulados ao seu projeto de vida, buscando desenvolver autonomia, foco e determinação (BNCC, 2017).

$\mathrm{O}$ fato de o curso estar sendo ministrado no campus de uma universidade, para o docente, também foi um ponto importante, pois permitiu ao aluno ter contato com o ambiente universitário ampliando sua a visão de futuro e a motivação para investir em carreiras diversas, não só a de um empreendimento próprio.

A educação financeira, que também é uma habilidade empreendedora, na opinião do docente não foi desenvolvida com profundidade. Para ele, o conteúdo de finanças seria mais efetivo se tivesse foco em finanças pessoais e questões o dia a dia, pois finanças para negócios ainda é uma realidade distante para a faixa etária dos alunos que frequentaram o curso.

Quanto aos pais que foram entrevistados, de forma individual, a maior contribuição do curso EJF foi a mudança de comportamento dos filhos, que são descritos como adolescentes sem foco ou perspectivas. Os pais observaram que seus filhos estavam mais organizados dentro de casa e na escola, com maior engajamento para as questões pessoais, e com mais perspectivas futuras de querer construir carreira, fazer faculdade. A iniciativa da UFF também foi destacada pelos pais.

\section{Análise dos resultados}

A abordagem da educação definida para o curso EJF pretendeu adotar uma perspectiva de educação para o empreendedorismo, e aliar teoria e prática, com o objetivo de dar aos empreendedores iniciantes os conhecimentos e habilidades necessários para empreender, foi enquadrada no Nível Base do Modelo de Progressão EntreComp, que contempla as dimensões descobrir e explorar. Na primeira, com supervisão direta (de professores, consultores, colegas, entre outros) o estudante se concentra na descoberta de suas potencialidades, interesses e desejos, e também em reconhecer diferentes tipos de problemas desenvolvendo aptidões e atitudes individuais. Na segunda dimensão, com apoio reduzido o estudante explora novas abordagens de problemas e se concentra na diversidade e em desenvolver 
aptidões e atitudes sociais. O programa EJF também utilizou o itinerário formativo empreendedorismo, proposto e chancelado pela BNCC para a escolha de competências empreendedoras a serem desenvolvidas durante a execução do programa.

O desenvolvimento de competências empreendedoras, que se dá pela união de fatores não-cognitivos, como por exemplo perseverança, autoeficácia, habilidades sociais, com fatores cognitivos que são as competências baseadas na capacidade intelectual. Segundo Lackéus, 2015, as competências cognitivas são fáceis de ensinar e avaliar, já as não cognitivas demandam uma forma de ensinar mais ativa, como "aprender fazendo" e é mais difícil de avaliar o desempenho (Lackéus, 2015).

No que tange a promover experiências que aliam a teoria e a prática, os formuladores do curso gostariam que os estudantes aprendessem colocando em prática competências empreendedoras. Os resultados sugerem que este objetivo foi atingindo parcialmente. Os estudantes demostraram muita dificuldade em acompanhar as atividades propostas e se mostraram muito imaturos para efetivamente implementar ações empreendedoras.

Uma outra competência que os formuladores do curso EJF gostariam que os alunos desenvolvessem e que vai de encontro com as abordagens e competências a serem desenvolvidas pela EE, é a educação financeira. Verificou-se que a abordagem escolhida para esta competência não foi adequada, os alunos não apresentaram maturidade suficiente para compreender totalmente o conteúdo proposto. De acordo com relatos do docente do curso, uma abordagem voltada para o cotidiano do aluno e o desenvolvimento de atividades onde os mesmos pudessem atuar em projetos no entorno da escola permitiria a eles observar resultados concretos de suas iniciativas, tornando mais efetivo o alcance dos objetivos de aprendizagem.

Por outro lado, foi verificado que o curso conseguiu promover o desenvolvimento de habilidades não cognitivas, tais como organização, criatividade, proatividade, autoconsciência, entre outras, conforme vários relatos dos entrevistados. Quando se analisa o desenvolvimento de competências empreendedoras, de forma lato sensu, em que os indivíduos tornam-se capazes de gerarem valor para a sociedade por meio das suas iniciativas, que não estão restritas a criação de empresa, conclui-se que as partes interessadas no EJF perceberam uma forte contribuição do programa neste aspecto.

O resultado da análise de conteúdo realizada por meio das transcrições dos áudios mostrou que todos os atores envolvidos na execução do programa concordaram, que os alunos assumiram maior protagonismo para resolver problemas e propor soluções para situações do cotidiano dentro e fora da escola, o que vai de encontro à proposta do Nível Base, do Modelo de Progressão EntreComp. Desta forma, os achados mostram que as competências agir por iniciativa, criatividade, comunicação, organização, autoconfiança, autoconhecimento e trabalho em equipe, puderam ser percebidas no comportamento dos jovens que frequentaram o EJF. Exemplos de mudanças no comportamento dos jovens também foram relatados. Jovens que eram impulsivos, que não se comportavam de forma adequada na escola ou dentro da sala de aula desenvolveram autocontrole e foram se tornando mais conscientes e "calmos" no dia a dia da escola, participando mais das aulas e interagindo melhor com professores, gestores e colegas de sala.

Os profissionais da organização REAME relataram o sucesso de um projeto de arrecadação de garrafas PET, em que o engajamento dos alunos foi de $100 \%$. Os estudantes 
participaram de forma ativa das atividades de planejamento de como seriam feitas as arrecadações, divulgação da ação, escala de pessoas para abranger todos os turnos da escola, entre outras atividades. Os profissionais relataram que as habilidades que os alunos estavam adquirindo no curso EJF foram fundamentais para colocar essa ação em prática. Aqui vale a pena destacar afirmação de Lopes, 2010, relacionando a educação empreendedora com a aprendizagem experiencial de David A. Kolb, onde sob essa perspectiva o homem é um ser integrado ao meio natural e cultural, capaz de aprender a partir de sua experiência motivado por seus propósitos, ou seja, obtém aprendizado através do que lhe faça sentido (Pimentel, 2007).

Referente a melhora no desempenho acadêmico, que poderia ser refletido no aumento das notas dos alunos, apesar de ter havido relatos de alguma contribuição neste sentido, não houve um consenso de que a EE melhorou as notas desses alunos. Os alunos relataram que mudaram a forma de organizar os estudos, sendo assim o engajamento no ambiente escolar acompanhou esta mudança contribuindo indiretamente nas demais atividades acadêmicas desenvolvidas pelos estudantes.

Para o docente entrevistado a maior contribuição do EJF foi acesso a ferramentas que possibilitaram desenvolver habilidades de gestão, organização e planejamento, que são úteis para o empreendimento, mas, também na condução de questões do dia a dia. $\mathrm{O}$ fato de o curso ter sido ministrado em uma universidade também foi um fator importante para ampliar a visão de futuro dos alunos. Ainda sob a perspectiva do docente, o contato com o ambiente universitário possibilitou que os estudantes aumentassem a percepção de que é possível seguir uma carreira universitária após o término do ensino médio, o que os levaria a ter maturidade sobre o caminho a seguir futuramente, ser empreendedor ou seguir outra carreira.

\section{Conclusão}

Esta pesquisa teve como objetivo principal analisar as contribuições de um programa de educação para o empreendedorismo, intitulado Empreende Jovem Fluminense (EJF), para o desenvolvimento de conhecimentos, habilidades e atitudes empreendedoras dos egressos a partir das percepções dos principais atores envolvidos na iniciativa.

No que se refere ao objetivo principal deste estudo, conclui-se que as habilidades não cognitivas foram mais bem percebidas pelos coordenadores das escolas, pela organização parceira e pelos pais ou responsáveis e estudantes. Já as habilidades de nível cognitivo foram mais percebidas pelo docente entrevistado. Segundo Lackéus (2015) as competências não cognitivas causam significativo impacto no desempenho acadêmico e nos resultados futuros do mercado de trabalho, talvez até mais do que as competências cognitivas. Desta forma, acredita-se que as contribuições do programa aqui analisado serão de grande importância para o desenvolvimento de uma carreira futura para os alunos que frequentaram o curso.

Como proposição de melhorias para o programa EJF este estudo sugere algumas ações, a saber: a) Revisão do escopo do curso ajustando a metodologia à faixa etária dos estudantes participantes, com vistas a tornar a apreensão do conteúdo mais eficaz; b) Reavaliação da plataforma online caso o formato do curso permaneça blended (presencial e EAD); c) Adequação do conteúdo de educação financeira à realidade dos alunos, utilizando casos práticos do dia a dia; d) Mudança do formato de entrega do projeto final. Sugere-se que 
o projeto final do curso seja elaborado a partir de demandas identificadas no dia a dia escolar ou da comunidade em que os alunos estejam inseridos.

\section{Referências}

Almeida, Rita K.;Packard, Truman G. Skills and Jobs in Brazil - An Agenda for Youth. International Bank for Reconstruction and Development / The World Bank. Washington DC. 2018.

Andersen, M., Hinz, B. and Matus, H. (2017). The Paradigm Shifters: Entrepreneurial Learning in Schools. Research report, Mitchell Institute Report No. 04/2017. Mitchell Institute, Melbourne.

Béchard J.P, G. D. (2005). Entrepreneurship Educaton Research Revisited: The Case of Higher Education. Academy of Management Learning \& Education, IV, pp. 22-43.

Bardin, L. (1977). Análise de Conteúdo. Lisboa: Edições 70.

Chen, S.-C., Hsiao, H.-C., Chang, J.-C., Chou, C.-M., Chen, C.-P., \& Shen, C.-H. (2013). Can the entrepreneurship course improve the entrepreneurial intentions of students? Int Entrep Manag J.

Chizzotti, A. (2006). Pesquisa Qualitativa em Ciências Humanas e Sociais. Petrópolis, RJ : Vozes.

Comissão Europeia/EACEA/Eurydice, 2016. Educação para o Empreendedorismo nas Escolas Europeias. Relatório Eurydice. Luxemburgo: Serviço de Publicações da União Europeia.

Dolabela, F.; Filion, L. J 2013. Fazendo revolução no Brasil: a a introdução da pedagogia empreendedora nos estágios iniciais da educação . Revista de Empreendedorismo e Gestão de Pequenas Empresas, v.3, n.2, p.134-181.

Fayolle, A. (2013). Personal Views on the Future of Entrepreneurship Education. Entrepreneurship and Regional Development: An International Journal, pp. 692-701.

Fayolle, A., Gailly, B., \& Lassas-Clerc, N. (2006). Assessing the Impact of Entrepreneurship Education Programmes: a new methodology. Journal of European Industrial Training, pp. 701-720.

Fonseca, J. J. S. (2002). Metodologia da pesquisa científica. Fortaleza: UEC. Apostila.

Gerhardt, T. E. \& Silveira, D. T. (2009). Métodos de Pesquisa. Porto Alegre: UFRGS.

Gil, A. C. (2008). Métodos e Técnicas de Pesquisa Social. São Paulo: Editora Atlas.

Hoare, M., \& Ruskovaara, E. (2015). Entrepreneurial Schools - Part 1 - Selected Institutional Guidance and Quality Management Approaches. Organization for Economic Cooperation and Development (OECD), Entrepreneurship360 - Thematic Paper.

Instituto Endeavor Brasil e SEBRAE. (2016). Empreendedorismo nas Universidades Brasileiras.

Johansen, V., \& Schanke, T. (2014). Entrepreneurship Projects and Pupil's Academic Performance: a study of Norwegian secondary schools. European Educational Research Journal, 13.

Lackéus, M. (2015). Entrepreneurship in Education: What, Why, When, How. Organization for Economic Co-operation and Development (OECD), Entrepreneurship 360 Background Paper. 
Lopes, R. A., \& Teixeira, M. A. (2010). Educação Empreendedora no Ensino Fundamental. In: R. M. (organizadora), Educação Empreendedora: conceitos, modelos e práticas (p. 230). São Paulo: Elsevier.

McCallum E., Weicht R., McMullan L., Price A. (2018). EntreComp into Action: get inspired, make it happen (M. Bacigalupo \& W. O'Keeffe Eds.) , EUR 29105 EN, Publications Office of the European Union, Luxembourg, 2018. ISBN 978-92-7979360- 8, doi:10.2760/574864, JRC10912.

Ministério da Educação. (06 de dezembro de 2016). Resultado do PISA 2015 é tragédia para o futuro dos jovens brasileiros, afirma ministro. Disponível em: http://portal.mec.gov.br/ultimas-noticias/211-218175739/42741-resultado-do-pisa-de 2015-e-tragedia-para-o-futuro-dos-jovens-brasileiros-afirma-ministro. Acesso em: 20 Set. 2018.

Ministério da Educação. (21 de Dezembro de 2017). Base Nacional Comum Curricular BNCC. Brasilia, DF, Brasil.

Ministério da Educação (2019). Programa de Apoio à Implementação da BNCC - ProBNCC Documento Orientador 2019. Brasília. Disponível em: http://basenacionalcomum.mec.gov.br/images/implementacao/doc_orientador_probnc c_2019.pdf.

Moberg, K. (2014). Assessing the impact of entrepreneurship education - from $\mathrm{ABC}$ to $\mathrm{PhD}$. Dinamarca.

Moberg, K., Vestergaard, L., Fayolle, A., Redford, D., Cooney, T., Singer, S., . . Filip, D. (2014). How to assess and evaluate the influence of entrepreneurship education. Dinamarca.

Neri, Marcelo. A educação professional e você no mercado de trabalho. Centro de Politicas Sociais, FGV, Brazil. 2009.

Organização Internacional do Trabalho. (s.d.). Tendências Mundiais do Emprego Juvenil. Acesso em 15 de junho de 2018, disponível em www.ilo.org: http://www.ilo.org/brasilia/centro-de-informacoes/documentos/lang--pt/index.htm.

Pittaway, L., \& Cope, J. (2007). Entrepreneurship Education - A Systematic Review of the Evidence. International Small Business Journal, pp. 479-510.

Programme for International Student Assessment - PISA (2018) Preparing our youth for na inclusive and sustainable world. The OECD PISA Competence Framework.

Ruskovaara, E. P. (2013). Teachers implementing entrepreneurship education classroom practices. Education and Training, v. 55, pp. 204-216.

Seikkula-Leino, J. R. (2012). Facing the changing demands of Europe: integrating entrepreneurship education in finish teacher trainning curricula. European Educational Research Journal, v.11, pp. 382-399.

Silva, Fernanda Góes da (2015). Ensino do empreendedorismo na educação básica: a formação do cidadão empreendedor em questão. 2015. 244f. Dissertação (Mestrado em Educação), Univás, Pouso Alegre.

Yin, R. (2001). Estudo de Caso Planejamento e Métodos - $2^{a}$ ed. (D. Grassi, Trad.) Porto Alegre: Bookman. 